\title{
Merit, Competition, Distinction ${ }^{1}$
}

\author{
Heidi Elmgren, University of Jyväskylä
}

\begin{abstract}
The article presents a critique of competition by introducing a concept called distinction. Competition is thought to work as a guarantee of the fairness of meritocratic procedures (merit-based recruiting in the job market or e.g. entrance examinations). However, fairness created by competition is, even at its best, only relative. This critique is then used a part of a larger critique of the role of merit in society.
\end{abstract}

Keywords: Competition, merit, interest, distinction

\section{Introduction}

In this article I present a critique of competition with the help of a concept I call distinction. ${ }^{2}$ This critique of competition is then used as a part of a larger critique of the role of merit in society, and in particular in hiring procedures in academia. Competition is thought to work as a guarantee of the fairness of meritocratic procedures, such as merit-based recruiting in the job market or the merit-based distribution of opportunities (e.g. entrance examinations for educational institutions). Upon closer examination, it becomes clear that fairness created by competition is, even at its best, only relative. Competition is used as the guarantee of the fairness of the meritocratic procedures, but it seems that the justification it aims to provide is also only relative. It appears that in order to rid ourselves of some of the problems related to competition, we ought to give up our current dominant concept of merit and the emphasis we place on it. 
I develop my argument with the help of two differentiations made by Dominique Girardot in her book La Société du mérite: Idéologie méritocratique et violence néolibérale (2011). She distinguishes between conflict and competition as well as between hierarchy and distinction. In section two of the paper I examine these four concepts and study their interaction. This is done in order to illuminate the importance and potential of one of the concepts, distinction, to the task at hand, namely, critiquing competition. In the third section, I explain the link between merit and competition and then proceed to look at the problems created by competition in the academic world. Combining my prior analysis with Marilyn Friedman's ideas about pluralism, I introduce distinc$\operatorname{tion}^{3}$ as a new criterion that could be used to challenge meritocratic and hierarchical competition as the main means of assessing and legitimizing recognition of merit. A procedure that could recognize distinction could help amend some of the problems created by competition. In the fourth section of the article, I examine how the concept of distinction resonates with Hannah Arendt's concepts of miracles and action, the latter of which is the human activity that is capable of starting something completely new. I compare the concept of miracle with Immanuel Kant's concept of genius. However, recognition of merit (which could include recognizing distinction, although at the moment it is most often not included) is linked to more general inclusion in society (having a job, access to training, participating in politics etc.). Due to this, in the fifth section I study how recognizing distinction can still strengthen unfairness and the exclusion of difference. Such a negative outcome is particularly probable if the subjective and intuitive sides intrinsic to distinction are not kept in check, such as when the objectivity of the procedure that can recognize distinction is not taken into consideration.

According to my interpretation, the problematic linked to competition, merit and exclusion is deep and solving it requires more than finding out what kind of procedure would produce the fairest outcomes. The problems related to merit are linked to social conditions in contemporary societies, and they cannot be mended by simply honing procedures that measure merit. My aim is to elucidate how the attempts to only fix procedures leave the conditions in which procedures are followed unquestioned. The focus of this article is twofold: it creates a critique of competition and consequently of merit-based exclusion by way of criticizing problematic procedures. Subsequently, I wish to explore a critique on a deeper level: to criticize the attempt to amend problems relating to merit-based exclusion simply by amending procedures. Our willingness to exclude someone based on any standard (no matter how well chosen) might always create more problems and unfairness than it claims to solve. In the absence of a better solution, aiming at creating procedures that could recognize distinction rather than aiming at establishing hierarchies might be better than doing nothing, but it should not lead us to think the problem has been solved. 


\section{Concepts}

In La société du mérite, Dominique Girardot discusses two differentiations: between conflict and competition and between a hierarchy and a distinction. I will take a look at these four concepts and examine how they interact.

\section{Conflict}

Conflict is central to recognition. ${ }^{4}$ Being in conflict means being in conflict with the definitions given to us by others and our own aspirations to be something we are not (yet are still recognized to be). Girardot writes that it is relationships with others that give a foundation for our identity. Thus, the recognition by others becomes extremely important for us (Girardot, 2011: 144-146). Conflict arises from the risk of not being seen by others as we wish to be seen.

According to Girardot, conflict enables a rivalry between subjects that is fruitful and not simply violent, a rivalry that is based on the (Arendtian) plurality of human subjects, the uniqueness of each human being from another and the inevitable multiplicity of viewpoints that follows. In this kind of rivalry the participants are equal and they are not aiming at showing that the other is wrong or less worthy than they themselves are. It seems Girardot is here following Chantal Mouffe and Ernesto Laclau's agonistic view of politics as she writes: "[this multiplicity of viewpoints] founds a political solidarity ... that is not ... manifested in the consensus but on the contrary in the confrontation of opinions that is never settled" (Girardot, 2011: 179). Later she continues on the topic of democracy, rivalry and equality: "Democracy is the affirmation of equality ...: it inscribes human beings to a rivalry by the [Maussian] gift rather than to the universal competition for the 'rare' goods" (Girardot, 2011: 202-203). The conflict and rivalry work within the paradigm of "the gift" Marcel Mauss described in his classic The Gift. The rivalry and the paradigm of the gift are intimately connected: the gift is always also a kind of show of excellence that the receiver can recognize but also refrain from recognizing. Giving reciprocally allows both to show greatness by giving, and act as worthy judges and appreciators of gifts that they receive (Mauss, 1999: 119-120). It can be interpreted that in societies based on the gift economy, it is the equality of participating peoples that enables the sublimation of certain aggressiveness in gift giving (Mauss, 1999: 134-135).

\section{Competition}

For Girardot, competition is the opposite of conflict. Competition is both individualizing and depersonalizing: although everyone competes as an individual, the competition makes the competitors impersonal. This is because in 
competition, the subjects are reduced to their qualities. They become the bearers (i.e. the supposed owners) of their qualities. These qualities are more or less rewarded (Girardot, 2011: 138-147.) As Girardot states, "To keep one’s place in the competition, it is important to develop characteristics that are analogic, comparable and measurable to those of others. ... Generalized competition banalizes and fragilizes identities, [the subjects] ought to keep to measurable conformities" (2011: 148). Competition, Girardot further suggests, demands competitors to become comparable. It thus encourages conformity rather than differing from pre-set standards.

According to Girardot (2011: 147), competition brings about a hierarchy instead of distinguishing. One might think, as Girardot notes, that neoliberal generalization of competition would help to produce social conditions that are the most favourable for the attainment of recognition. With competition becoming omnipresent, would not this enable people to reveal themselves more frequently, and thus be a positive thing? It is an often-repeated belief that the best will always prevail and competitions are situations where excellence can be manifested. According to Girardot, this is not the case. The structure of competition prevents recognizing all there is to be recognized. This is because exclusion is competition's founding principle. Competition works within a framework of scarce goods to which there is limited access. There simply are not enough positions for everyone to reveal themselves. (Girardot, 2011: 146; Girardot, 2016, private email.) The ideology of merit works as a justificatory tool that assures that efforts will be rewarded although, for instance, (politically created) economical scarcity will most certainly preclude that.

As opposed to competition, the conflict in the search for recognition circulates around reflexivity and makes people notice how alone and hollow they are without others. People need other people, and they need them also for the recognition they can give (Girardot, 2011: 146.) However, unlike conflict, competition turns others into enemies, as Girardot (2011: 143) puts it, because one person's success in competition always means a failure for everyone else competing. Competition prevents the opening towards others and to what is different from oneself. Competition prevents people from truly encountering each other, and this is linked to the way competition builds hierarchies (Girardot, 2011: 147). ${ }^{5}$

\section{Hierarchy}

The conflictual nature of recognition demands that people recognize the other as an equal, as someone who can recognize them or withdraw their recognition from them. Hierarchy means the explicit denial of equality. Hierarchy is nowadays often justified by (supposedly) objective competition. Hierarchy separates people from each other, diminishes mutual recognition and justifies 
treating others as less worthy. ${ }^{6}$ Competition and the hierarchy it creates are ways to evade recognizing equality. If there is a ranking from better to worse, there is no need to claim equality. There is no equality, because some are better than others.

Hierarchical relations thus seem harmful for recognition. I next develop Girardot's claim that hierarchy effaces distinction. What is distinction and why is the disappearance of distinction problematic?

\section{Distinction}

In her critique of competition, Girardot writes that competition does not distinguish, but instead creates hierarchies; in other words, it does not create distinctions (Girardot, 2011: 147). Therefore, the distinction that competition does not create must be something that does not necessarily lift one above others (to create a hierarchy). Yet distinction still has to be somehow remarkable because it is brought about in a conflict, where there is room for mutual recognition and fruitful rivalry. This means that distinction can be recognized, that it can be something we admire. Girardot also points out that competition demands comparability, and for this reason, competitions create conformity rather than singularity (Girardot, 2011: 147-148). Instead of this, distinction can be something relatively incomparable: it could reflect singularity. Based on these distinctive features set by Girardot, non-comparability, remarkability and non-hierarchy, the term distinction could capture something that is excellent and original, combined with differing from the norm and pre-set standards. This means recognizing that it is a question of reflection, not of calculation or deduction - of judgment, to use Hannah Arendt's term (Arendt, 1992: 3-5).

To avoid measuring that kills the possibility of recognition, we should aim at creating procedures that have the potential of recognizing distinction. However, recognition, even of distinction, is never absolute. The emphasis should therefore be on aiming at creating such procedures and, through those, striving for outcomes that allow for a certain newness and unpredictability. The nonhierarchic nature of distinction has interesting implications. It seems to follow that in a hierarchy, attaining recognition is much harder than in an equal setting. In a hierarchy, one can receive recognition only from one's superiors and the recognition one receives is not attainable by anyone else. Equality enables conflict, which can result in fruitful rivalry where all participants can simultaneously aim at becoming better in their fields but not be directly threatened by others' success. A procedure that recognizes distinction does not require the selection of one single winner and the exclusion of all the rest. Rather, it could recognize several, equal "winners". The resulting procedure that could recognize distinction thus has a certain utopian aspect about it. 


\section{Examining the Academic Context: Distinction, Pluralism, Gender}

\section{Merit and Competition}

In this section I use the academic world as an example to explicate the role of merit in competition and how competition and merit create problematic situations. The problems relating to competition in academia are widely known and criticized by many scholars. For instance, Carson, Bartneck, and Voges (2013) analyze how competitions are inefficient ways of distributing funding, and Hawkins, Manzi, and Ojeda (2014) elucidate the negative effects of competitive academic culture on the wellbeing and mental health of researchers. I want to contribute to these findings with a philosophical analysis of the limitations of competition and problems relating to merit-based exclusion.

One way to amend the situation is to demand more carefully devised competitions. However, a wider critique still might be needed. As Carson et al. and Hawkins et al. note, criticizing so-called bad competition is not enough. It might be necessary to question the principle of competition altogether.

First, we should identify some problems relating to competition:

1) Bad judging and bias: unfair choices by selection committees caused by implicit or explicit bias. This can be tackled by setting the composition of the committee in such a way as to prevent anyone's personal opinions from dominating the selection. (See the notes on Longino in the next subsection.)

2) Problematic criteria: even when the committee is well selected and personal biases can be ruled out, the criteria can still cause biased outcomes and favour certain forms of excellence over others, such as only taking into consideration the quantity and not the quality of written works, overlooking teaching as an academic merit and so on. This can be tackled by being conscious of the various outcomes and consequences different criteria have.

Above I presented the first problem as having been solved, but the second one persists. Equally, the situation may be vice versa: the criteria may be well chosen but the personal biases of selection committees can still cause biased outcomes.

3) Competition forces sameness: usually, in order to take part in a competition, one needs to meet the criteria of the competition. Taking part in competitions demands competitors to be similar and this rules out diversity in several, interwoven ways. In complex social situations, setting overly narrow criteria may have problematic consequences. Women and men tend to choose different specialties in philosophy and, as Katrina Hutchinson (2013: 123) points out, journals publishing papers only relating to certain specialties end up excluding more women than men. 
On another level from these is a fourth problem, which I tackle in the fifth section of the paper:

4) The material and political conditions in which competitions are organized. There is a scarcity of jobs yet finding employment is necessary in order to maintain a sufficient standard of living.

It is curious that competition has become such a crucial part of academic work. Most would agree that competition is parasitic to the actual goal of universities: attaining knowledge. To use Mika La Vaque-Manty's term, unlike in sports, competition is not "a constitutive norm" of the academic world (La Vaque-Manty, 2009). In my view, the omnipresence of competition in academia is linked to the value placed on merit. The principle of merit is taken to work as a guarantee of fairness and of the good quality of scientific work. Merit works as an assurance to ensure that no one receives something they are not entitled to. Proof of merit is demanded to achieve the ideal of academia as a meritocracy: that the ones who are recognized (by having won the competition) are the most meritorious, experienced, and prominent researchers in their field. Yet numerous studies show that this is not the whole story. Embarking on an academic career has a lot to do with luck, connections, family background, race, age, sex, nationality and other aspects. ${ }^{7}$ To be precise, I am not claiming that people working in academia are without merits, but it is clear they are there partially by chance, not just by merit.

What is merit, then? For the purposes of this article, merit is anything that is viewed as a merit in a given situation. However, we cannot define it in a completely relativistic way. It is clear that in many situations we want merits to be clearly defined. For example, we require that surgeons have careful training and maybe even official qualifications. When it is a matter of life and death, this use of merit seems indisputable. However, in other contexts, for example in the artistic setting, matters are less clear. When no one's life is at imminent risk, the standards, methods and reasons for acting are varied and their evaluation is not a self-evident task. For instance, giving Bob Dylan the Nobel Prize in literature in 2016 was a seen as choice that was somehow outside the box. It was an opening towards a different kind of excellence (songwriting) than the one that is usually considered worth the prize (writing novels). Especially in the specific context of art almost anything can be a merit, especially in the context of distinctions: something new that escapes pre-set standards and qualifications yet is still appreciated.

The conditions for something to be seen as a merit are that it needs to be possible to (a) give reasons that (b) some of the others can understand and (c) accept for considering it to be a merit. This means that the merit needs to match certain criteria. But in order to maintain the possibility for something new to emerge, the reasons given for considering something a merit may be new criteria in that situation, because a distinct performance can make it possible to question the earlier norms. 


\section{Distinction and Competition in Academic Work}

Let us consider one particular example of the problematic between distinction and competition in academic work. Often, one cannot, in a reasonable sense, decide which of two excellent job applications for a position in philosophy is better, as they are written by two different persons with different specialties, conceptual and methodological starting points, tasks and goals. The candidates are simply too different. They do not settle into a hierarchy but both stand as excellent and distinct from each other. Sara Heinämaa has pointed out that, to be precise, neither is aiming only at conforming to well-established academic or theoretical norms but, in so far as they operate creatively, they also establish their own norms. ${ }^{8}$ These two different persons and their ways of practicing philosophy are nevertheless compared when deciding who should be hired for a position in a given philosophy department. There is relatively little space for recognizing the distinction of both the applicants.

Of course, it is not simply due to the mechanisms of competition that both of the applicants cannot be recognized equally: most often only one person can be hired for a given position. ${ }^{9}$ However, one problematic outcome of the mechanisms of competition seems to be that of the philosophers who are actually hired, an overwhelming majority are white males (see e.g. Rini, 2013). Girardot's observation that competition creates similarity seems to gain a particular meaning in this context. If the majority of applicants are white males, then it seems that the similarity of candidates (i.e. the similarity of people who enter a career in philosophy) has been established already before the competition takes place. Alternatively, if there were a nearly equal amount of male and female candidates, ${ }^{10}$ the gender gap that nevertheless prevails in philosophy departments seems to suggest that not only specialties but other characteristics of the competitors are assessed and interpreted as merits and demerits. I will continue with this topic in the next section.

If competitions are as problematic as these reflections indicate, how can we replace them and with what? At the least, it seems it would be good if the procedure that is used in an assessment of any kind could recognize distinction, but what would this mean? Following from the definition of distinction sketched out in section 2, I would like to argue that something that is distinct can question the norms that govern assessment. Let us imagine a running contest where one competitor has decided not to compete in running fast, but in running gracefully. Let us further imagine that they succeed in such a way that the judges feel compelled to negotiate whether the competitor should be given an honourable mention (fittingly by its other name, a distinction). Recognizing distinction demands recognizing what is personal and original in the act, recognizing its singularity. Grace, as such, cannot be measured like speed, but it is a matter of judgment. However, the recognition of such a singular act cannot be forced or demanded as a due. The incomparable competitor deliberately 
takes the risk of being disqualified or simply overlooked. The conflict and striving for recognition that Girardot claims is lost in competition is reclaimed in this kind of setting where there is room (or where someone makes room for) the unpredictable. The recognition that the graceful runner possibly, only possibly, attains, is therefore all the more precious.

This example is obviously not very realistic - someone might even call it amusing. It has been pointed out to me that a better example would be Oscar Pistorius, the athlete with artificial limbs who competed in London in the 2012 Summer Olympics. However, unlike the graceful runner, Pistorius was, remarkably, becoming comparable with the other athletes who did not share his handicap. He was trying to be faster than the others, simply with different means - artificial legs instead of biological ones. The graceful runner seems to be taking a different kind of chance: they are defying the rules and hoping to be recognized. Their action could be read as being almost a critique of serious, single-minded running. Pistorius' accomplishment is without question extraordinary, but it is not distinction in the sense used here.

Now we can return to our example of two different job applicants at a philosophy department. In an assessment that respects distinctions, there is no single winner above all but several, equal "winners". In an article concerning the exclusion of women and minority groups as well as marginal topics and approaches in philosophy, Marilyn Friedman has suggested pluralizing meritocratic standards of evaluation as a solution for the exclusion problem (Friedman, 2013). Pluralizing the standards could help bring about distinctions rather than hierarchies. Plural standards demand a wider expertise and, in practice, the pluralization would most likely best be achieved by having more people doing the assessment. The objectivity of science would benefit from this: objectivity can more likely be achieved by a community where different people's biases cancel each other out, so to speak, rather than by individuals (Jukola, 2015.) The problem here is that no matter how objective or sensitive to distinction the hiring process is, the material conditions where hiring decisions are made do not usually allow for hiring more than one person. Pluralizing the selection committee and the standards is, in practice, a difficult task with surprising obstacles (see Ahmed, 2016), and it might be even more difficult to increase (to pluralize literally) the amount of people the committee can hire. There simply are not enough positions for everyone. The several, equal "winners" cannot all be hired.

To summarize, here are the differences between Pistorius, the graceful runner and philosophers with different specialties. Pistorius is not changing (at least the goals) of his chosen game, instead, he has shown that different kinds of people can compete in it too. The graceful runner is doing something quite revolutionary, at least for a while. The runner might be starting a new game (maybe parkour or even a combination of ballet and running), which could 
later become a strict and non-reflective sport obsessed with its own rules, thus falling back on the competition logic.

Philosophers with different specialties are not, in a way, competing in the same game at all even though the competition actually brings them to compete against each other. The problem is that some specialties seem to be more esteemed than others. There seem to be hierarchies within philosophy affecting which specialties and what kinds of questions are deemed more deeply philosophical than others (Hutchinson \& Jenkins, 2013). This inequality of specialties is manifested, for instance, in the Finnish JUFO classification of academic journals. The most esteemed journal of feminist philosophy, Hypatia, is graded 2 out of 3 (Pölönen \& Roth, 2015). This means that for someone specialized in feminist philosophy it is virtually impossible to publish in the highest category. Among other things, this affects hiring feminist philosophers for positions in philosophy departments. ${ }^{11}$

This means that to argue that specialties cannot be compared because they are too different is not enough. They may well be incomparable, but it does not change the fact that some specialties are more valued than others and therefore they are more likely to be favoured.

The problem of inequality here is linked to power positions: who ranks scientific journals? Who makes the decision to hire yet another white male candidate with a "highly similar CV"? This is the level where the change should happen. Or could it be that the problem is wider? Does it start with our difficulty to imagine institutions without hierarchies? It is not often problematized that only a few people are allowed to decide for so many. Hierarchy demands that there are always fewer people on the upper levels, meaning there are simply not enough positions for everyone who are qualified.

In their critical article about academic competitiveness, Carson, Bartneck and Voges ask:

What prevents us from opening our eyes to the absurdity of the academic situation? Why are we so convinced that our proposal will be accepted? Why do we believe that we will achieve a tenured process and that our paper will be accepted by $\mathrm{Na}$ ture? Coming back to Alice's question "Who won the race?" we conclude that currently we are all losing. (Carson et al., 2013: 189)

In the Caucus Race in Alice in Wonderland, which the authors are referring to, the contestants do actually get warm and dry despite not finding out who finally won the race. In that sense everyone wins. In academic competitions, however, these kinds of beneficiary side effects are less evident. The alternative Carson et al. propose for distributing funding is a lottery. This would require no energy from the applicants, so they could focus on their actual scientific work. The authors have are now creating computer simulations that test the ef- 
ficiency of funding in the long run compared to the current system (Carson et al., 2013). The fairness of such a lottery procedure could be argued to be questionable. However, in addition to being very inefficient, the current system is often heavily based on the role of references of the application and therefore might not be as fair as we wished anyway. A system that awards funding for the first year simply by lottery and which demands a progress report on the project for subsequent years would save significant time for researchers who stand to possibly gain nothing, yet the quality of scientific work would not be as compromised as in a system that requires no reporting at all.

\section{Distinction, Newness, and Miracles}

It seems clear there is a subversive element in distinction. Distinct action questions and rewrites the norms that govern assessment: it asks to be recognized on its own terms because it is creating something new in the world, something that Hannah Arendt calls a miracle. This possibility of a miracle does not need to be extremely rare. For Arendt, the concept of the miracle can be abstracted from the religious framework and refer to any new, unlikely event. The existence of our planet and human beings are examples of miracles for her.

[W] henever something new occurs, it bursts into the context of predictable processes as something unexpected, unpredictable, and ultimately causally inexplicable - just like a miracle. In other words, every new beginning is by nature a miracle when seen and experienced from the standpoint of the processes it necessarily interrupts. (Arendt, 2005: 111-112)

To recognize miracles, we need to use our faculty of judgment, which "has ... to do with man's ability to make distinctions" (Arendt, 2005: 102).

For Immanuel Kant, it is only the few geniuses who can truly use their ability to change the course of history and make miracles. For others, it remains to follow the lead of such geniuses (Boehm, 2013: 171). Instead, for Arendt, the human condition of natality, the "birth of new men and the new beginning" is "the miracle that saves the world" (Arendt, 1958: 247). Everyone is capable of beginning, of starting something new. She identifies the creation of man with the creation of freedom (Arendt, 1958: 177). She continues: "This character of startling unexpectedness is inherent in all beginnings and all origins ... The fact that man is capable of action means that the unexpected can be expected from him, that he is able to perform what is infinitely improbable" (Arendt, 1958: 178). It is not some rare genius who is able to do this, but man, any human being. Also, for Arendt, the ability to judge, to make distinctions even when confronting something new to which earlier standards do not apply, is 
"quite familiar" and "can be seen in everyday life whenever, in some unfamiliar situation, we say that this or that person judged the situation rightly or wrongly" (Arendt, 2005: 102).

There is a stark difference between Kant's and Arendt's ideas on miracles and genius. It seems that for Arendt, actions are great, even genius, whereas for Kant, it is the people behind those great actions that are geniuses. What I find interesting is that the Kantian idea of a rare genius is still very much present in contemporary society. For instance, Sally Haslanger has recounted her negative experience of being told by one of her teachers that he had "never seen a first rate woman philosopher and never expected to because women were incapable of having seminal ideas" (Haslanger, 2008). In this teacher's view, some people (usually men) "have it" and some simply do not. This is a common way of understanding genius or talent: it is thought to be something bestowed only upon a few people. The idea of rare geniuses has consequences on our conception of merit, recognition and who is recognized. If we expect miracles only from a few people, then what most people are doing has to be interpreted as mediocre.

Expecting miracles only from a few can be backed up by claiming that only a few people actually do something exceptional. Often there is talk of potential and attempts to locate it, either with tests or intuitively so that it could be guaranteed that no resources are wasted on those who lack potential. The problem with potential is that it is truly potential; in order to become visible and real, it needs to have a chance to actualize. Potential is not something that leaves marks and indications to be picked up by some method. It is, to a great extent, a question of belief. To give potential the space (and time!) to actualize means always taking the risk that the actualization will not take place. But failing to give potential a chance makes it extremely probable it will not develop. The fact that, against all odds, some people manage to succeed even with virtually no resources does not mean others who are equally unprivileged just 'don't have it', that they are lacking something. It means they are less lucky and that the society in which they live is simply unfair.

The recognition of distinction is not simple. To recognize the emergence of something new, we need wonder, as described by Luce Irigaray and interpreted by Sara Heinämaa (2016). Irigaray is referring to René Descartes' passion of wonder. Wonder is a passion that "doesn't involve any value-judgment" of its object (Descartes, 2010: \$53, \$70-73). However, as Heinämaa notes, for Descartes, wonder is always a "spontaneous reaction" whereas for Irigaray wonder is an ethical principle, a task that ought to be carried out in order to act ethically. Heinämaa argues that Irigaray's concept of wonder is equally influenced by Maurice Merleau-Ponty's description of the phenomenological method. According to Heinämaa, for Irigaray, wonder means "refraining from measuring the other by our own cognitive and emotional standards" (Heinä- 
maa, 2016). This "suspension of evaluation" (ibid.) allows us to open towards what is new. I wish to argue that wonder can become a way by which to learn to appreciate something new, by opening towards it.

Instead of opening towards what we cannot instantly define and understand, it is easy to settle, with Kant, to deem something as "lacking spirit" (Kant, 1914: \$49). For Irigaray, wonder is "not something that happens to us" (Heinämaa, 2016) like it is for Descartes - and possibly also for Kant, given his idea of wonder as "a shock of the mind" that "provokes a doubt as to whether we have rightly seen or rightly judged" (Kant, 1914: \$62). Instead, wonder is for Irigaray a "particular passivity that requires activity"; it is something "we have to struggle for" (Heinämaa, 2016). Heinämaa argues that "wonder depends on the other" but that it is "my task to maintain this opening". I would like to take this notion a little further. In order for us to be ethical subjects, which is the aim of Irigaray's project, could wonder sometimes be something that we need to try and evoke despite the immediate lack of it, despite the apparent "lack of spirit" in for example, a musical performance? With a closer examination, it may be revealed that "spirit" is not simply the attribute of a person or a cultural product, but also dependent on the people who assess whether or not something has it. The whole situation where the "spirit" ought to express itself takes part in the creation of the spiritedness of, for instance, a musical performance. If this is true, we need to ask: to whom do we allow the benefit of suspending our first impressions - that is, the benefit of wonder - before deeming them this way or that? Who is allowed to distinguish themselves? Who is given the time to develop their potential to actuality? Who is deemed crazy, a mediocrity or a genius? The idea of distinction faces deep problems that are linked to cultural power positions and implicit values, especially in a culture where this "Kantian" conception of genius as someone who prevails against all odds reigns. I will concentrate on this problematic in the next section.

\section{The Problem with Distinction: Intuition and the Idea of Genius}

So far I have criticized non-pluralistic competition for the way it produces conformity and builds hierarchies which prevent mutual recognition. However, what I call distinction could face different kinds of problems and cause a similar situation where only people with "highly similar CVs and forms of excellence" (Jenkins, 2013: 99) are hired: namely white (young) men.

There is an objection to my arguments about the need to recognize distinction. If to recognize distinction means to let go of at least some of the pre-set standards of assessment and give way to wonder and by wonder to admira- 
tion, it seems this kind of reaction is more likely to be provoked and tolerated if the person behind them is our stereotypical genius: a straight, white male. One might argue that this danger is particularly present in philosophy. Katrina Hutchinson (2013) has written about the difficulty women have in building and embodying authority in philosophy. Authority is a relational attribute: others must agree that you have authority in order for you to have it. As Haslanger's example of "seminal ideas" suggests, it is often thought that there is something about, for instance, philosophy, that cannot be learned but which already needs to be there. This type of thinking is problematic and can be and has been criticized. Also, as Jennifer Saul (2013: 43-44) suggests, the difficulty people have in recognizing their own implicit biases which affect their assessment is possibly stronger within the philosopher population. People who think they are objective are more likely to be less so (Uhlman $\&$ Cohen, 2007), and because the main virtue of philosophers is often thought to be objectivity, this seems to create a dangerous combination where implicit bias reigns.

So what can be done if people's own feelings about their own objectivity are mostly erroneous, and if even when people have a realistic conception of their level of objectivity, it means that they know they are unobjective? How are we to reach objective outcomes at all? Helen Longino's studies on objectivity show that it is, indeed, difficult for a single human being to attain objectivity. However, the problem is not as desperate as one might think based on this conclusion. Objectivity can instead be present in a community, given that the community is diverse enough (see e.g. Husu and Rolin, 2005; Jukola, 2015). This takes us back to the crucial role of pluralism. Achieving diversity requires a wide base of expertise in decision-making bodies. In an article concerning the position of women in philosophy (Elmgren, 2016), I suggested one way to enhance the situation and women's participation in philosophy would be to tackle the inequality of different subfields in philosophy. First, hiring different kinds of people from various subfields of philosophy and then making them members in the committees that decide who will be hired next could make it more likely that non-male, non-white, non-analytical philosophers are also hired.

\section{Conclusions: To the Root of the Problems}

It might seem that the problems are neatly solved. If we could just create better hiring procedures and gather a larger crowd of people to assess the applicants for positions in academia, the outcome of those procedures would be fairer and more objective. But this is not enough. 
There are a number of problems on several levels here. Some of them can be tackled by making sure that procedures are not biased and standards are not so strict that they hamper anything new from emerging. However, some of the problems remain unsolved and, what is worse, they are responsible for maintaining an even deeper problem than the ones of lower orders, namely: if improving the procedure actually enables the meritocratic system of exclusion to continue, is it, then, actually harmful?

On the first level:

1) Biased competition: not everyone has the same chance at obtaining the positions, access to education and so on that they would deserve based on their merits.

On the second level:

2) The nature of competition: it creates conformity rather than enables distinction.

3) The idea that there is a scarcity of human talent in the world that is only bestowed upon a few and those few can be identified in some manner, be it competition, testing, or intuition.

4) Even if distinction is recognized in some way, the recognition of distinction is likely to be unequal because it is affected by power positions, cultural and social valuations, and discrimination.

On a societal level:

5) The role of competition in society: we use competition in the job market to justify exclusion from professions that require expert skill, but these practices also have much wider consequences. Because general inclusion in society is conditioned by the person's taking part in working life, the scope of exclusion becomes wider. Generalized competition can exclude an individual from more wide-ranging possibilities to enhance the quality of one's life as well as from wellbeing and health.

No matter how fair the competition is, if we require everyone to take part in it and create a situation where all who might have the qualifications still cannot find a job, there remains serious unfairness in the situation as a whole. If we do not have enough jobs in society, then seeing employment as a prerequisite for social inclusion and participating in society is simply unfair, no matter how well it can be shown that all who have jobs are among the best in their respective fields. The situation is unfair, no matter how much the hired ones deserved their jobs.

We may solve problems $1-4$ by improving meritocratic procedures that are used in for instance hiring. Insofar as we are not able to change society as a whole, it might be more important to enhance the fairness of our existing procedures and thereby enable more people (as well as different kinds of people) to manage in competition. But if this allows us to close our eyes from the deeper social unfairness, it becomes a dubious task. If I endorsed this position, whose 
cause would my article and its conceptual analysis further? The cause of those who are already privileged, who have qualifications but are left unrecognized due to first and second level problems or of those who are outside the entire competition framework? Yet whose cause is more urgent? The answer seems obvious.

My more radical solution (instead of merely improving procedures) would be to dissociate education level from the level of one's salary, control the levels of salary with income caps and introduce a substantial basic income. Basic income would eliminate the need for every individual to have a job because their survival would not depend on having one. If monetary compensation was not seen as the main means of showing appreciation for someone's job, it would also help end the discussion on whether, for instance, a job requires so much merit that a salary of an astronomical scale is necessary to match the given effort. We cannot completely abolish the need to assess the quality of people's work in some manner (because many jobs do require expert skill). Despite this, the suggested changes would amend the inclusion of people who, for whatever reason, are not in the job market, and keep income differences on a more sustainable level. This would be beneficial to all as income level equality has been shown to enhance the wellbeing of the whole population (Wilkinson $\&$ Pickett, 2009: 302-303).

If we continue to imagine that we can simply modify meritocratic procedures to their maximum capacity and decide for certain and for good that someone deserves a given position, we are likely to continue the unfair exclusion of people who have not received the same opportunities in life as have those we consider to have merits.

\section{Endnotes}

1 I would like to thank Martina Reuter for her insightful comments during the process of writing this article.

2 This article is a part of my dissertation on the problematic created by meritocracy in contemporary society. In this article I concentrate on questions of merit, recognition and procedures that aim at finding out who (e.g. among applicants for a given job) is most meritorious. What merits are, exactly, is not the key question of this article; merits may be whatever are the characteristics or qualifications that are viewed as merits in a given situation. I elaborate on this definition in section 3.

3 This should not be confused with Pierre Bourdieu's concept.

4 The concept of recognition used in this paper is that of Dominique Girardot, which is influenced by Axel Honneth's thought. The difference is that in Honneth's system recognition is divided into three forms: emotional support, cognitive respect and social esteem. Girardot mostly speaks simply of recognition but also makes a division between respect, which is for everyone due to their unique- 
ness, and admiration, which refers to recognition of remarkable deeds and people. (On the differences between Honneth and Girardot, see Elmgren 2015). This article mostly concerns admiration, in Girardot's terms: the recognition of remarkable things and the possibility of recognizing something that breaks from earlier standards of assessment.

5 It has been pointed out to me that for instance in an election the juxtaposition between competition and conflict is misguided; lack of competition in an election would be telling of a one-party system rather than an indicator of a good process. The juxtaposition is not meant to be absolute but to refer to particular evaluating practices. A democratic election is not the type of competition that is described here: at least in principle, it does not force the competitors to become identical but instead, an election can be won in more than one way, leaving room for distinction (see below). Of course people do compete for votes in an election but the competition itself can be "played" and won in several ways (although, in practice, money seems to play a central role). Democracy is not (at least necessarily) meritocracy and therefore the problems of merit do not directly apply to it.

6 I would like to thank Martina Reuter for pointing me towards this conclusion.

7 On how racism affects embarking on an academic career, see Altbach \& Lomotey (1991) and Walker (2003); on the effect of social class, see Soria \& Stebleton (2013); on the interplay between race and social class, see Hardaway \& McLoyd (2009); on the interplay between race and class on women, see Gutierres y Muhs et al. (2012); on sex discrimination in British academia, see Knights and Richards (2003); on women's worse career prospects in academia, see Danell \& Hjerm (2013).

8 Heinämaa, private email 2015.

9 Getting the job is obviously not the only way to become recognized. However, being recognized, for instance, formally (in the form of a certificate or a more general "thumbs up" from the assessment board) while not getting the job is still a rejection and leaves the other equally qualified candidate in a precarious situation.

10 It is also a well-known fact that there is a serious lack of diversity in philosophy departments. In this paper I have concentrated on the case of women because this problem is the most well documented (see e.g. Beebee \& Saul 2011; Hutchinson \& Jenkins 2013), but the situation seems to be even worse for people of colour and people who do not conform to traditional gender norms. On the situation of Black students in philosophy, see Fernandes Botts et al. 2014.

11 The impact is not necessarily direct, because the creators of the JUFO classification system explicitly emphasize it should not be used to evaluate individual researchers. However, the classification is used in measuring the productivity of departments and thus researchers with so-called better JUFO scores may be more likely to be hired or tenured etc. 


\section{References}

\section{Books and articles}

AHMED, Sara, 2016. Feminism and Fragility. A blog post based on a lecture from a forthcoming book by Ahmed Living a Feminist Life. Available online: https:// feministkilljoys.com/2016/01/26/feminism-and-fragility. Accessed 31 October 2018.

ALTBACH, Philip G. \& Lomotey, Kofi, 1991. The Racial Crisis in American Higher Education. Albany: State University of New York.

ARENDT, Hannah, 2005. The Promise of Politics. New York: Schocken Books.

ARENDT, Hannah, 1992. Lectures on Kant's Political Philosophy. Chicago: University of Chicago Press.

ARENDT, Hannah, 1958. The Human Condition. Chicago \& London: University of Chicago Press.

BEEBEE, Helen \& Saul, Jennifer, 2011. Women in Philosophy in the UK. A report by the British Philosophical Association and the Society for Women in Philosophy UK. Available online: http://www.bpa.ac.uk/uploads/2011/02/BPA_Report_Women_In_Philosophy.pdf. Accessed 19 June 2015.

BOEHM, Omri, 2013. Enlightenment, Prophecy, and Genius: Kant's Critique of Judgment versus Spinoza's Tractatus Theologico-Politicus. Graduate Faculty Philosophy Journal, 34:1, 149-78. New York: New School for Social Research.

CARSON, Lydia; Bartneck, Cristoph, \& Voges, Kevin, 2013. Over-Competitiveness in Academia: A Literature Review. Disruptive Science and Technology, 1:4, 183-190. Available online: http://online.liebertpub.com/doi/abs/10.1089/dst.2013.0013

DANELL, Rickard \& Hjerm, Mikael, 2013. Career Prospects for Female University Researchers Have Not Improved. Scientometrics, 94:999. Available online: http:// link.springer.com/article/10.1007/s11192-012-0840-4.

DESCARTES, René, 2010. The Passions of the Soul. Available online: http://www. earlymoderntexts.com/assets/pdfs/descartes1649part2.pdf. Accessed $\longdiv { 3 1 \text { October } }$ 2018.

ELMGREN, Heidi, 2015. Recognition and the Ideology of Merit. Studies in Social and Political Thought, 25: Special issue: Pathologies of Recognition. Available online: http://www.sussex.ac.uk/ojs/index.php/sspt/article/view/32/29. Accessed 31 October 2018.

ELMGREN, Heidi, 2016. Naiset filosofiassa: tilaa distinktiolle? In Rolin, K. \& Moisio, O-P (eds.), Sukupuoli ja filosofia. Jyväskylä: Sophi. Available online: http:// urn.fi/URN:ISBN:978-951-39-6610-2. Accessed 31 October 2018.

FERNANDES BOTTS, Tina; Bright, Liam Kofi; Cherry Myisha; Mallarangeng, Guntur \& Spencer, Quayshawn, 2014. What Is the State of Blacks in Philosophy? Critical Philosophy of Race, 2:2, 224-242.

FRIEDMAN, Marilyn, 2013. Women in Philosophy: Why Should We Care? In K. Hutchinson \& F. Jenkins (eds.), Women in Philosophy: What Needs to Change? Oxford: Oxford University Press.

GIRARDOT, Dominique, 2011. La Société du mérite - idéologie méritocratique \& violence néolibérale. Lormont: Le Bord de l'Eau. 
GUTIERRES Y MUHS, Gabriella; Flores Niemann, Yolanda; Gonzáles, Carmen G. \& Harris, Angela P. (eds.), 2012. Presumed Incompetent: The Intersections of Race and Class for Women in Academia. Logan, UT: Utah State University Press.

HARDAWAY, Cecily R. \& McLoyd, Vonnie C., 2009. Escaping Poverty and Securing Middle Class Status: How Race and Socioeconomic Status Shape Mobility Prospects for African Americans During the Transition to Adulthood. Journal of Youth Adolescence, 38:242.

HASLANGER, Sally, 2008. Changing the Ideology and Culture of Philosophy: Not by Reason (Alone). Hypatia, 23:2, 210-223.

HAWKINS, Roberta; Manzi, Maya; Ojeda, Diana, 2014. Lives in the Making: Power, Academia and the Everyday. ACME: An International Journal for Critical Geographies, [S.1.], 13:2, 328-351. Available online: http://142.207.145.31/index.php/ acme/article/view/1010. Accessed: 16 January 2018.

HEINÄMAA, Sara, 2016. Wonder as the Primary Passion: A Phenomenological Perspective on Irigaray's Ethics of Difference. In L. Dolezal and D. Petherbridge (eds.), Body/Self/Other: Phenomenology of Social Encounters. Albany: SUNY Press.

HUSU, Liisa \& Rolin, Kristiina, 2005. Tiede, tieto ja sukupuoli. Helsinki: Gaudeamus.

HUTCHINSON, Katrina, 2013. Sages and Cranks: The Difficulty in Identifying First-rate Philosophers. In Hutchinson, K. \& Jenkins F. (eds.), Women in Philosophy: What Needs to Change? Oxford: Oxford University Press, 103-126.

HUTCHINSON, Katrina \& Jenkins, Fiona (eds.), 2013. Women in Philosophy: What Needs to Change? Oxford: Oxford University Press.

JUKOLA, Saana, 2015. On the Conditions for Objectivity: How to Avoid Bias in Socially Relevant Research. Doctoral dissertation. Jyväskylä: University of Jyväskylä.

KANT, Immanuel, 1914. Critique of Judgment. London: MacMillan. Available online: http://oll.libertyfund.org/titles/kant-the-critique-of-judgement. Accessed 31 October 2018.

KNIGHTS, David \& Richards, Wendy, 2003. Sex Discrimination in UK Academia' in Gender. Work and Organization, 10:2, March, 213-238.

MANTY-LAVAQUE, Mika, 2009. The Playing Fields of Eton: Equality and Excellence in Modern Meritocracy. Ann Arbor: University of Michigan Press.

MAUSS, Marcel, 1999. Lahja. Vaihdannan muodot ja periaatteet arkaaisissa yhteiskunnissa. [Essai sur le don] Helsinki: Tutkijaliitto.

SORIA, Krista M. \& Stebleton, Michael J., 2013. Social Capital, Academic Engagement, and Sense of Belonging among Working-Class College Students. College Student Affairs Journal, 31:2, 139-153.

UHLMANN, Eric Luis \& Cohen, Geoffrey L., 2007. "I think it, therefore it's true": Effects of Self-Perceived Objectivity on Hiring Discrimination. Organizational Behavior and Human Decision Processes, 104:2, 207-223.

WALKER, Polly, 2003. Colonising Research: Academia's Structural Violence towards Indigenous Peoples. Social Alternatives, 22:3, 37-40.

\section{Websites}

PÖLÖNEN, Janne \& Savolainen, Eeva, 2018. Julkaisufoorumi (Publication forum). Online address: www.julkaisufoorumi.fi. Accessed 1 November 2018. 